\title{
Industry 4.0 and Developing Countries: Innovation Perspective of Ethiopia, India and Bangladesh
}

\author{
Amrutrao ${ }^{1}$ | Ravindra Pathak ${ }^{2}$ | Ashraf Mahmud Rayed ${ }^{3}$ \\ $1 *$ School of Mchanical and Automative Engineering, Dilla University, Dilla , Ethiopia \\ $2^{*}$ Department of Mechanical Engineering, Medi-Caps University,Indore, India, \\ ${ }^{3}$ Department of Mechanical Engineering, Chittagong Univarsity of Engineering and Technology, Chittagong, Bangladesh.
}

To Cite this Article

Amrutrao, Ravindra Pathak and Ashraf Mahmud Rayed, "Industry 4.0 and Developing Countries: Innovation Perspective of Ethiopia, India and Bangladesh", International Journal for Modern Trends in Science and Technology, Vol. 06, Issue 06, June 2020, pp.:62-70; https://doi.org/10.46501/IJMTST060615

Article Info

Received on 27-April-2020, Revised on 24-May-2020, Accepted on 30-May-2020, Published on 07-June-2020.

\section{ABSTRACT}

Ethiopia, India and Bangladesh are raising economic power, but have not yet integrated very much with the global economy and still have not achieved their potential in context of technology, globalization, and international competitiveness like developed countries. These countries have much strength, but at the same time, are facing many challenges in the increasingly competitive and fast changing global economy.

The main key strengths of these courtiers are their large domestic market, young and growing population, a strong private sector with experience in market institutions, and a well developed legal and financial system.

In today's environment of global competition, technological development and innovation; companies, especially manufacturing, are forced to reconfigure their manufacturing and management processes. Industry 4.0 and intelligent manufacturing are part of a transformation, in which manufacturing and information technologies have been integrated to create innovative systems of manufacturing, management and ways of doing business. This system allows optimizing manufacturing, to achieve greater flexibility, efficient production processes and generate a value added proposal for their customers, as well as to provide a timely response to their market needs.

The objective of this work is to explore the Industry 4.0, smart manufacturing, environment requirement and relation of innovation in perspective of developing countries.

KEYWORDS: Ethiopia, India, Bangladesh, Innovation, Industry 4.0

Copyright (C) 2014-2020 International Journal for Modern Trends in Science and Technology

DOI: https://doi.org/10.46501/IJMTST0606015

\section{INTRODUCTION}

This research has traced the strategies of the Industry 4.0 implementation and in perspective of Ethiopia, India, and Bangladesh which have not been performing as well in Industry 4.0. From the comparisons it may be inferred that the key elements of the successful strategies of these economies have been a strong outward orientation, heavy use of foreign knowledge (including copying and reverse engineering and otherwise appropriating foreign knowledge), macroeconomic stability, high investment rates, and an economic incentive and institutional regime that demands improved performance. All of them except other developing economy, these countries made extensive use of investment as a way to acquire foreign knowledge and to penetrate export markets. India opted not to rely on investment, but to acquire knowledge through trade, and reverse engineering, and to invest substantially in its own 
research and development[1,2]. It also invested massively in internet and then infrastructure development. These high levels of facilitated its assimilation of foreign technology and the development of its own technological capability.

The recent growth performance of these countries is based on natural resource rents rather than on technological capability. Thus it appears that a common strategy for most of the high performers was to start with labour intensive exports and to gradually move up to more sophisticated products $[3,4,5]$.

\section{Innovations ANd Developing Countries}

Innovation in the context of developing countries is not so much a matter of pushing back the frontier of global knowledge, but more the challenge of facilitating the first use of new technology in the domestic context. Innovations should be considered broadly as improved products, processes, and business or organizational models. Development strategists ought to think not only of research and development $(\mathrm{R} \& \mathrm{D})$ and the creation of knowledge, but also attend to the details of its acquisition, adaptation, dissemination, and use in diversified local settings $[4,5]$.

The creation of knowledge is the process of inventive activity. It is usually the result of explicit research and development effort normally carried out by scientists and engineers. The key institutions involved in the creation of knowledge are public $R \& D$ laboratories, universities, and private R\&D centres. However, not all creation of knowledge is the result of formal $R \& D$ effort. Sometimes inventions come from the experience of production, or through informal trial and error; sometimes they come from serendipitous insight. Notably, the multiple origination of knowledge raises a measurement problem because not all $\mathrm{R} \& \mathrm{D}$ activity results in an invention, and not all inventions come from formal R\&D activity. Nonetheless, various proxies are available to track knowledge, R\&D effort, and their interconnections. Accordingly, the most standard proxies will be applied as needed in the following discussion. For countries behind the technological frontier, acquisition of existing knowledge may be expected to yield higher increases in productivity than would flow from a similar scale investment in $R \& D$ or other efforts to push back the technological frontier. There are many means of technology transfer for private goods[6]. Direct foreign investment, licensing, technical assistance, importation of technology as embodied in capital goods, components or products, copying and reverse engineering, and foreign study are the key channels. Also, more generally, easy communication allows access to technical information in printed or electronic form, especially including what can be accessed through the internet. Proprietary technology is usually sold or transferred on a contractual basis. But even proprietary technology may leak out depending on the strength of the Intellectual Property Rights (IPR) regime and its enforcement, and the reverse engineering capacity of users. However, despite significant proprietary constraints, much of the most useful technology is in the public domain or is owned by governments who could potentially put it in the public domain. As such, the key challenges for Technology, Globalization, and International Competitiveness development strategy are less about the creation and acquisition process and more often related to the challenges of delivering technology and knowledge to those who need it. Technologies often must undergo adaptation to be applicable in specific local conditions [7].

\section{Methodology}

To contextualize the object of study and have a critical assessment of previous research, as well as to contrast the findings and methodological approaches used, the systemic literature review was selected as an exploratory and analytical technique for the collection of information.

To carry out the same, the two-state approach was followed, which is based on identifying the most relevant and rigorous research stored in recognized databases to guarantee the quality and veracity of the information used. Initially, we searched for articles related to Industry 4.0, problems in developing countries published on the Web, Web of Science and Google Scholar; subsequently, we proceeded to review its content, select those related and they were classified and analysed.

Also, it was sought to theoretically support the main technological components associated with industry 4.0 and smart manufacturing. Every time the information was structured, the implicit components and technologies were mapped and conceptualized in order to show how the theoretical foundations on which Industry 4.0 and smart manufacturing rests are being strengthened. Subsequently, based on the aforementioned 
references, the technological and support architecture that make up Industry 4.0 was determined, as well as the expected benefits and future prospects. From this analysis, some of the implications that this technological initiative is expected to have in industry, business and employment were established. Finally, a web search was carried out on the initiatives for Industry 4.0 implemented in India, Ethiopia and Bangladesh with the results achieved.

\section{INDUSTRY 4.0}

The concept of Industry 4.0, emerged in Germany in 2011 , to refer to a government economic policy based on high-tech strategies [8]; characterized by automation, digitization of processes, and the use of electronic and information technologies in manufacturing [9]. Likewise, for the personalization of production, the provision of services and the creation of value-added businesses. And, due to the interaction and information exchange capacities between humans and machines [9].

Throughout history, technological development has had a major impact on manufacturing systems, first with the steam engine and the mechanization of processes, then with mass production, automation, and robotics; and more recently, with what has been called "industry 4.0" and is already considered the "Fourth Industrial Revolution", due to its potential and benefits related to integration, innovation and process autonomy. The concepts of industry 4.0 and smart manufacturing are relatively new and contemplate the introduction of digital technologies in the manufacturing industry. That is, the incorporation into the manufacturing environment of technologies such as the Internet of Things, mobile computing, the cloud, big data, wireless sensor networks, embedded systems and mobile devices, among others $[10,11]$.

Some of these technologies have already been used for years, but in isolation; however, its integration an possible capabilities is what the empowers to transform the manufacturing industry, with fully integrated, automated and optimized production processes; and with significant results in improving operational efficiency and organizational performance [9]. The impact of this technological transformation is such that it is affecting all aspects of the organization, from production and organization to research and development, as well as inventory control, management and customer support, etc. [10]. Likewise, the business vision and performance is changing. Its impact has been such that industry 4.0 is already considered as a systemic innovation process that redefines business models and provides a fully integrated global perspective of the environment and organization [11].

Industry 4.0 is underpinned by systems development, the Internet of Things (IoT) and the Internet of people and services [12, 13]; coupled with other technologies such as additive manufacturing, 3D printing, reverse engineering [14], big data and analytics, artificial intelligence, etc., which when working together, are generating significant changes not only in the manufacturing industry but also in consumer behavior and in the way of doing business. And, at the same time, they favour the construction of capacities that allow companies to adapt to market changes [14].

The conceptualization that exists about industry 4.0 is recent, however, it has been defined as a physical machinery and devices with sensors and software that network and allow better prediction, control and planning of business and organizational results [16]. Also, as a term associated with the technologies and concepts of the organization's value chain $[17,18]$, which describes a production oriented to cyber-physical systems (CPS); systems with physical and computational capabilities that can interact with humans, that integrate production facilities, storage and logistics systems, as well as the establishment of networks for the creation of value [19]. Industry 4.0 represents an approach to the innovation of new products and processes, through smart factories, fully integrated into work networks (throughout the value chain) that foster new forms of collaboration and social infrastructure [20].

However that, it is still in the development process, its benefits allow us to anticipate great changes, since it is associated with the digitization of information and production systems for management activities; automation systems for data acquisition from machines and production lines; with the exchange of information for monitoring and control of processes and decision-making in real time [21,22], to name a few.

In this same order of ideas, intelligent manufacturing is considered as the ability to digitally represent every aspect of manufacturing, from design to manufacturing - using software tools such as design and computer-aided 
manufacturing (CAD / CAM), systems for product life cycle management (PLM) and the use of analysis, simulation and management software, etc. [23]. This type of manufacturing emphasizes the use of digital methods for planning and validating all stages of manufacturing, from product development to production and facility planning [24]; To this end, it relies on a set of technologies that not only facilitate the prior validation of products and manufacturing processes, but also make it possible to reduce new product development times, manufacturing costs and manufacturing batches [25]. In other words, they make manufacturing more flexible, improve product quality, and speed up market response times [26, 27].

From this perspective, the changes that are taking place in manufacturing are the product of the technologies that are being developed for: 1) The digitization of production, 2) Automation, 3) The integration of capabilities (through cyber-physical systems) 4) And for manufacturing like 3D printing, reverse engineering, smart machining etc. $[25,28]$.

So, in this context, Industry 4.0 is a new level of value chain organization and management [29], which is likely to change the way processes, supply chain, and business models operate [ 30], which is why many companies are evaluating the concepts and applications synthesized under the term Industry 4.0 to develop their own business strategies [31], which under this new industrial disruption, is founded on some basic principles such as interoperability, virtualization, decentralization, real-time capabilities, service orientation, etc., [32] and where there are, for example, smart factories capable of creating virtual copies of the physical world, monitoring physical processes, self-managing, optimizing, and making decisions autonomously in real time [21].

\section{TECHNOLOGIES ASSOCIATED WITH INDUSTRY 4.0}

Within the technologies that support the industry 4.0 and smart manufacturing cover simulation, additive manufacturing, horizontal and vertical integration systems, cyber security, augmented reality, cloud computing, autonomous robots, the industrial internet of things and big data and advanced analytics. Also, social technologies, cyber-physical systems and open collaboration, mobile devices (tablets, phones), platforms and technological applications, as well as artificial intelligence and information technologies [33].

Although there is no consensus on this, the Internet of Things (IoT), mobile computing, cloud computing and big data and advanced analytics seem to be the most important technological pillars in Industry 4.0, given that of these technologies, depends: 1) The scalability of computing capacity, 2) Data processing and analysis, 3) The global accessibility of services via the internet or other mobile devices and 4) The creation of new processes, products and business models [8, 34].

Through the Internet of Things, systems can interact with each other and with humans in real time. The Internet of Services (IoS) is the means by which it is possible to offer and access them [35]. While big data, cloud computing, and artificial intelligence are enablers of Industry 4.0 and along with industrial automation they are changing the way products are manufactured; they contribute to the improvement of manufacturing $[36,21]$ and that companies have fully automated and interconnected processes that facilitate the flow of information, the decentralization of manufacturing, the creation of new processes, decision-making and an approach to the development of competencies that add value to organizations $[23,21]$ in such a way that not only greater innovation of products and processes is generated; but also smart factories and other business models [18]. And at the same time, the supply chain is improved; key strategy to increase the competitive position and profitability of organizations.

Hence, the integration of all the company's activities together with those who interact in the supply chain, suppliers, customers and partners, within broad networks, is a core activity in organizations, and technology is the best means to design, create and implement such environments [37] that facilitate the exchange of information, products and services [38], the taking advantage of opportunities and creating competitive advantages.

Consequently, companies are moving towards technological architectures that allow them to achieve higher levels of integration. For example, to optimize the logistics and efficiency of its supply chain $[18,36]$ and ensure product traceability [37] in less time and cost. Likewise, to improve their adaptability to the market, the use of resources and the demand and supply process. These architectures are part of the products, machines, 
factories, services and even smart cities characteristic of Industry 4.0 [38].

Industry 4.0 refers to technologies and concepts of the organization of the value chain in smart factories, which have in their structure cyber-physical systems (CPS) capable of monitoring physical processes, creating a virtual copy of the real world and making decisions decentralized. Therefore, the CPS is expected to provide solutions that transform the operation and role of many of the existing industrial systems. In the Industry 4.0 vision, machines will be able to communicate with each other to receive or transmit information and execute actions; the products will be smart [38], since with the IoT, many networked sensors will be able to be embedded in devices and machines and will display enormous amounts of data of different types, and cloud computing will provide solutions for the storage and processing of these large volumes of data [37].

However, this large amount of data, generated in a massive way, will also require sensors with other types of technology and greater capacities [33], for example, for intelligent signal processing, network communication and remote solution of complex tasks. Likewise, smarter solutions will be needed for its management and organization; along with technological platforms and communication protocols that guarantee the flow, processing and security of information [39]. Consequently, the IoT and Industry 4.0 will also influence the way in which customers, suppliers and wholesalers, etc. interact, who will be able to have a greater participation in the process and the decisions about the manufacturing, quality and customization of the products. products; considering, of course, the cyber security challenges involved that guarantee having a solid structure for information exchange and collaboration [40].

Also, new requirements will be needed for the wireless communication, mobile and cloud computing, to name a few, which will impact the design, development and deployment of networks for emerging applications, for example; and they will also promote the creation of other types of cyber-physical systems, with greater capacities, more aware of the environment and assisted in the cloud [41]. Finally, cloud manufacturing will continue to be the new manufacturing paradigm and business model, which will favor service-oriented, highly collaborative, knowledge-intensive

and

sustainable manufacturing [42].

Based on this theoretical review, the components of Industry 4.0 that was mostly pointed out in these investigations. Accordingly, the main components revolve around cyber-physical systems, smart machines and products, the internet of things, the internet of services, as well as factories and smart cities. Also, some of the technologies that are considered as subcomponents of the former.

The analysis of the information presented on industry 4.0 allows us to have a broader vision of the scope, benefits, implications and challenges of this fourth industrial revolution. The findings found are consistent with previous studies, in which it has been pointed out that Industry 4.0 encompasses a set of technologies that allow the integration of products in interconnected physical and digital processes [43]; and that the smart factory is a new dimension of manufacturing management that uses the state of the art of computing technologies and tools [44], with a significant impact on supply chains and business models and processes [45]. In the same way, they are similar regarding the importance of some base technologies for the provision of global access services via the internet (internet of services), such as cyber-physical systems, the internet of things, mobile and cloud computing, and big data [46, 34,]. Likewise, there are similarities in terms of the support architecture under which Industry 4.0 is concerned, its benefits and implications [12, 20, 33]. These are summarized in aspects associated with flexibility, productivity, competitiveness and access to global markets $[39,40]$, as well as with decreasing costs and increasing profitability.

Based on this perspective, Industry 4.0 is expected to increase the digitization of manufacturing, work networks are created that will allow a greater interaction of humans and machines; and information exchange and analysis, supported by the advancement of technologies such as big data and cloud computing (web hosting services) [24], which will reconfigure manufacturing for more flexible, efficient production of lower cost and more sustainable, as well as a better integrated value chain with important benefits in operational efficiency, productivity and competitiveness [21, 29, 31] and therefore in organizational profitability.

Undoubtedly, two of the trends and challenges will be related to the required technological 
developments, for example, the cyber-physical systems that underpin all innovations in both service and manufacturing [26], which will include how to improve them, make them more reliable and provide them with greater capabilities and, of course, how to implement them, [56]. The deployment of these systems is what allows synchrony to exist between physical and virtual space; and that the information can be sent and monitored [21]. Along with smart sensors and systems, as well as modern information and communication technologies that will provide the flexibility, adaptability and autonomy that new manufacturing systems will need [28].

What, in the future it is to be expected that cyber-physical manufacturing systems (CPPS), (autonomous, cooperative and interconnected elements and subsystems at all levels of production) dominate manufacturing; are integrated into machines and products; and at the same time combine computing capabilities, networking, and physical processes within manufacturing processes [35]. There is also the use of emerging information technologies to implement the Internet of Things (IoT) and services (IoS) in engineering and business processes in order to equip organizations with better systems, more integrated, flexible and sustainable [39]. The IoT will be the platform that will satisfy the need to manage, automate and explore all devices, instruments and sensors; and will support decision making [40].

However, other aspects will have to be observed, since the success of the implementation of these technologies will depend, to a large extent, on the network integration capabilities that can be built to facilitate collaboration, the creation of flexible and reconfigurable manufacturing systems and the integration engineering throughout the value chain to support this new type of manufacturing [39, 37].

In the context of Industry 4.0, both machines and products will have powerful microprocessors and artificial intelligence technologies, with which they will have computing, communication and control (3C) skills, as well as autonomy and sociability. And industrial networks and the internet will facilitate the interconnection between them; while cloud computing technology will provide the storage space and computing capacity necessary for the management and analysis of large volumes of data [39, 29]. IoT and IoS will continue to be part of the manufacturing processes that will drive this new industrial revolution [38] and will provide new functionalities to management processes and support systems that will help organizations to have better architectures and more automated [40].

In smart factories, devices will have decision capabilities [31], while also being connected to manufacturing and management systems [32]; and they may be operated by individuals or by artificial intelligence [32]. In other words, flexible manufacturing systems will be created that will produce large volumes of data through various devices, which will be transferred to the cloud and processed with different systems. Furthermore, information and services can be easily accessed with mobile and cloud computing, [44] from anywhere in the world.

Similarly, the application of information technologies will continue to be one of the main potentializers of such opportunities and at the same time a generator of competitive advantages [44], since they will facilitate not only a greater integration of the supply chain, but they will also allow reducing uncertainty, life cycles, inventories and will foster greater collaboration among all those involved in the value chain [39]. Along with other methods and techniques of business architecture, which will be improved and will continue to be used to strengthen the manufacturing and management industry, such as information systems for business resource planning (ERP), the execution of manufacturing (MES), manufacturing process management (MPM), etc., which allow integrating and interoperating processes and sharing information throughout the company and the value chain [39].

In this order of ideas, modern manufacturing will require new technological developments, for example, more interoperable, intelligent, adaptable integration models, distributed under an architecture service-oriented and cloud computing. In addition to others, to strengthen manufacturing in the cloud [43] and so that the factories of the future can configure their (cyber-physical) systems with other technologies [44]. Like other countries, a series of initiatives have been launched in Indian IT companies to incorporate the country's companies into the fourth industrial revolution and accelerate the adoption process. This includes the elaboration of the technological road map, programs for the diffusion of technologies, applications and the benefits that can be expected through it; and establishing strategies to adopt these. However, 
efforts must be redoubled to promote their knowledge and boost their implementation.

Lastly, the vision of Industry 4.0 seems to be one in which "smart" factories will have global networks that will incorporate cyber-physical systems into machinery, storage systems and production facilities. In the manufacturing environment, these CPS will facilitate the exchange of information, the execution of actions and the control of each one autonomously, which will generate improvements to the industrial processes involved in manufacturing engineering, materials, supply chain and life cycle management [45]. Such a smart factory will also produce smart products that will know how they were produced; they will transmit data as they are being used; data that will be collected and analyzed in real time [46] for decision-making and the development of new products and business opportunities.

\section{Conclusions}

In this perspective of Industry 4.0, innovation is becoming a more critical element of competitiveness. Developing countries have to be constantly innovating to avoid falling behind. This does not necessarily mean that they have to be moving the technological frontier forward. Only the most advanced countries do that. However, all developing countries need to be at least fast imitators and adopt, use and improve new technology in order not to fall behind. This puts a great deal of pressure on technological capabilities. Moreover, innovation is not just a matter of new products or new processes and ways to produce them, but also better organization and management techniques, and better business models which facilitate doing business.

The implication of this for developing economy is that they have to make greater efforts to keep up with new technologies and new forms of business organization and production and distribution networks. This requires more investment in their technological capability to search for, acquire and adapt technology to their needs and in managing production and distribution systems. For those that are closer to the frontier, it means that they need to put more effort into real cutting edge innovations in technology and business.

The finding in the literature reviews enough information to conceptualize the terms related to industry 4.0 and smart manufacturing. Likewise, to have a clearer understanding of what the technologies associated with them are, along with the transformations, implications, benefits and expected challenges resulting from them. Given the importance that this technological disruption has not only in manufacturing, but also in the formation of human capital and in new business models, information and knowledge about the advances and benefits of these are key elements for establishing the knowledge and support bases that allow entrepreneurs to be sensitized and trained on the importance of their organizations moving towards industry 4.0 and smart manufacturing, since it is the means through which productivity can be promoted and competitiveness of developing economics.

The scope as well as the implications of this global technology initiative are still difficult to quantify, but it is known that Industry 4.0 and smart manufacturing will optimize manufacturing systems, shorten the development cycle of new products, reduce manufacturing costs and will allow for fully integrated and automated production processes, with machines capable of self-managing and maintaining itself; that they will provide information that will be possible to access globally in real time, through the internet and various mobile devices, thereby facilitating the creation of cooperation and collaboration networks; and, in the same way, better decision making. However, an important aspect to consider is that in order to achieve this, it is required, first of all, not only the establishment of government initiatives, but also the participation of educational institutions to spread their knowledge and train human resources with the competences that these new technologies require. Secondly, to establish some strategies that allow companies to accompany the implementation process; this, through the training of specialized consultants; and a national strategy that contributes to facilitating this process and creating all the supporting infrastructure that is required to venture into it, such as cyber security and communication issues, to name a few.

As main challenges for its implementation in developing countries are lack of strong investment in technology and new set of skills related to data management and analysis, computer-aided production, online simulation, programming.

\section{REFERENCES}

[1] Bakshi, S. K., and I. Kumar. 2013. India and Sustainable Development Goals (SDGs). Policy brief, November 2013. Energy and Resources Institute, New Delhi, India. 
[2] Alauddin, M. (2003a) 'Trade and Regional Integration Issues for Bangladesh: Predicaments and Prospects', in M. Hossain, AKM Nurrunabi and I. Islam (eds.), Bangladesh's Development Agenda and Vision 2020: Rhetoric and Reality, Dhaka: University Press Limited, pp.91-107..

[3] Alauddin, M. (2003b) 'Economic Liberalization and Environmental Concerns: A South Asian Perspective', South Asia, 26 (3), pp.439-53.

[4] Tisdell, C.A. and Alauddin, M. (2003) 'Market-oriented Reforms and Poverty in Bangladesh', in K. Sharma (ed.), Trade Policy, Growth and Poverty in Asian Developing Countries, London: Routledge, pp.189-201.

[5] Narasimha M, Ramesh S (2015) Enhancing Ethiopian industrial growth by original equipment manufacturing. Journal of Multidisciplinary Engineering Science Studies 1(1): $1-8$

[6] Rama MR, Simon ZT (2015) Performance measurement of manufacturing industries in Ethiopia-An analytical study. Journal of Poverty, Investment and Development (7).

[7] Drath, R. and Horch, A. (2014), "Industrie 4.0: Hit or hype?", IEEE Industrial Electronics Magazine, Vol. 8 No. 2, pp. 56-58.

[8] Burmeister, C., Luettgens, D. and Piller, F.T. (2015), "Business Model Innovation for Industrie 4.0: Why the 'Industrial Internet' Mandates a New Perspective on Innovation", Ssrn, No. January,

[9] Lee, J., Bagheri, B. and Kao, H.A. (2015), "A Cyber-Physical Systems Architecture for Industry 4.0-based Manufacturing Systems", Manufacturing Letters, Society of Manufacturing Engineers (SME), Vol. 3, pp. 18-23.

[10] Kolberg, D. and Zühlke, D. (2015), "Lean Automation $\begin{array}{llll}\text { enabled by } & \text { Industry }\end{array}$ Technologies", IFAC-PapersOnLine, Vol. 48 No. 3, pp. $1870-1875$.

[11] Lasi, H., Fettke, P., Kemper, H.G., Feld, T. and Hoffmann, M. (2014), "Industry 4.0", Business and Information Systems Engineering, Vol. 6 No. 4, pp. 239-242.

[12] Brettel, M., Friederichsen, N., Keller, M. and Rosenberg, M. (2014), "How Virtualization, Decentralization and Network Building Change the Manufacturing Landscape: An Industry 4.0 Perspective", International Journal of Mechanical, Aerospace, Industrial, Mechatronic and Manufacturing Engineering, Vol. 8 No. 1, pp. 37-44.

[13] Bonekamp, L. and Sure, M. (2015), "Consequences of Industry 4.0 on Human Labour and Work Organisation", Journal of Business \& Media Psycology, No. 1, pp. 33-40.

[14] Kans, M. and Ingwald, A. (2016), "Business Model Development Towards Service Management 4.0", Procedia CIRP, The Author(s), Vol. 47, pp. 489-494.

[15] Lee, J., Kao, H.A. and Yang, S. (2014), "Service innovation and smart analytics for Industry 4.0 and big data environment", Procedia CIRP, Elsevier B.V., Vol. 16, pp. 3-8.

[16] Li, X., Li, D., Wan, J., Vasilakos, A.V., Lai, C.F. and Wang , S. (2017), "A review of industrial wireless networks in the context of Industry 4.0", Wireless Networks, Vol. 23 No. 1, pp. 23-41.

[17] Oesterreich, T.D. and Teuteberg, F.

(2016), "Understanding the implications of digitisation and automation in the context of Industry 4.0: A triangulation approach and elements of a research agenda for the construction industry", Computers in Industry, Elsevier B.V., Vol. 83, pp. 121-139.

[18] Shrouf, F., Ordieres, J. and Miragliotta, G. (2014), "Smart factories in Industry 4.0: A review of the concept and of energy management approached in production based on the Internet of Things paradigm", IEEE International Conference on Industrial Engineering and Engineering Management, Vol. 2015 No. January, pp. 697-701.

[19] Weyer, S., Schmitt, M., Ohmer, M. and Gorecky, D. (2015), "Towards Industry 4.0 - Standardization as the crucial challenge for highly modular, multi-vendor production systems", IFAC-PapersOnLine, Elsevier Ltd., Vol. 48 No. 3, pp. 579-584.

[20] Ohno, T. (1988), Toyota Production System: Beyond Large-Scale Production, 1st ed., Productivity Press.

[21] Qin, J., Liu, Y. and Grosvenor, R. (2016), "A Categorical Framework of Manufacturing for Industry 4.0 and beyond", Procedia CIRP, The Author(s), Vol. 52, pp. 173-178.

[22] Sanders, A., Elangeswaran, C. and Wulfsberg, J. (2016), "Industry 4.0 implies lean manufacturing: Research activities in industry 4.0 function as enablers for lean manufacturing", Journal of Industrial Engineering and Management, Vol. 9 No. 3, p. 811.

[23] Stock, T. and Seliger, G. (2016), "Opportunities of Sustainable Manufacturing in Industry 4.0", Procedia CIRP, Elsevier B.V., Vol. 40 No. Icc, pp. 536-541.

[24] von Tunzelmann, N. (2003), "Historical Coevolution of Governance and Technology in the Industrial Revolutions", Structural Change and Economic Dynamics, Vol. 14 No. 4, pp. 365-384.

[25] Theorin, A., Bengtsson, K., Provost, J., Lieder, M., Johnss on, C., Lundholm, T. and Lennartson, B. (2017), "An event-driven manufacturing information system architecture for Industry 4.0", International Journal of Production Research, Taylor \& Francis, Vol. 55 No. 5, pp. 1297-1311.

[26] Wang, S., Wan, J., Zhang, D., Li, D. and Zhang, C. (2016b), "Towards smart factory for industry 4.0: A self-organized multi-agent system with big data based feedback and coordination", Computer Networks, Vol. 101, pp. $158-168$.

[27] Zhong, R.Y., Xu, X., Klotz, E. and Newman, S.T. (2017), "Intelligent Manufacturing in the Context of Industry 4.0: A Review", Engineering, Elsevier LTD on behalf of Chinese Academy of Engineering and Higher Education Press Limited Company, Vol. 3 No. 5, pp. 616-630.

[28] Zezulka, F., Marcon, P., Vesely, I. and Sajdl, O. (2016), "Industry 4.0 - An Introduction in the phenomenon", IFAC-PapersOnLine, Elsevier B.V., Vol. 49 No. 25 , pp. 8-12.

[29] , K., Liu, T. and Zhou, L. (2015), "Industry 4.0: Towards future industrial opportunities and challenges", 2015 12th International Conference on Fuzzy Systems and Knowledge Discovery (FSKD), IEEE, pp. 2147-2152.

[30] Wollschlaeger, M., Sauter, T. and Jasperneite, J. (2017), "The future of industrial communication: Automation networks in the era of the internet of things and industry 4.0", IEEE Industrial Electronics Magazine, Vol. 11 No. 1, pp. $17-27$.

[31] Posada, J., Toro, C., Barandiaran, I., Oyarzun, D., Stricke r, D., de Amicis, R., Pinto, E.B., et al. (2015), "Visual Computing as a Key Enabling Technology for Industrie 4.0 and Industrial Internet", IEEE Computer Graphics and Applications, Vol. 35 No. 2, pp. 26-40.

[32] Prause, G. (2015), "Sustainable Business Models and Structures for Industry 4.0", Journal of Security and Sustainability Issues, Vol. 5 No. 2, pp. 159-169.

[33] Saldivar, A.A.F., Li, Y., Chen, W.N., Zhan, Z.H., Zhang, J. and Chen, L.Y. (2015), "Industry 4.0 with cyber-physical integration: A design and manufacture perspective”, 2015 
21 st International Conference on Automation and Computing: Automation, Computing and Manufacturing for New Economic Growth, ICAC 2015, No. September, pp. 11-12.

[34] Sauter, R., Bode, M. and Kittelberger, D. (2015), "How Industry 4.0 Is Changing How We Manage Value Creation", Horvárt, No. 1, pp. 3-11.

[35] Grangel-Gonzalez, I., Halilaj, L., Coskun, G., Auer, S., Col larana, D. and Hoffmeister, M. (2016), "Towards a Semantic Administrative Shell for Industry 4.0 Components", Proceedings - 2016 IEEE 10th International Conference on Semantic Computing, ICSC 2016, pp. 230-237.

[36] Hermann, M., Pentek, T. and Otto, B. (2016), "Design Principles for Industrie 4.0 Scenarios", Proceedings of the Annual Hawaii International Conference on System Sciences, Vol. 2016 No. March, pp. 3928-3937.

[37] Faller, C. and Feldmúller, D. (2015), "Industry 4.0 learning factory for regional SMEs", Procedia CIRP, Elsevier B.V., Vol. 32 No. Clf, pp. 88-91.

[38] Gorecky, D., Schmitt, M., Loskyll, M. and Zühlke, D. (2014), "Human-Machine-Interaction in the Industry 4.0 Era", Proceedings - 2014 12th IEEE International Conference on Industrial Informatics, INDIN 2014, pp. 289-294.

[39] Kagermann, H. (2015), "Change Through Digitization-Value Creation in the Age of Industry 4.0", Management of Permanent Change, Springer Fachmedien Wiesbaden, Wiesbaden, pp. 23-45.

[40] Erol, S., Jäger, A., Hold, P., Ott, K. and Sihn, W. (2016), "Tangible Industry 4.0: A Scenario-Based Approach to Learning for the Future of Production", Procedia CIRP, Elsevier B.V., Vol. 54, pp. 13-18.

[41] Schmidt, R., Moehring, M., Haerting, R.C., Reichstein, C., Neumaier, P. and Jozinovic, P. (2015), "Industry 4.0 Potentials for Creating Smart Products: Empirical Research Results", Lecture Notes in Business Information Processing, Vol. 208, pp. 16-27.

[42] Thoben, K.D., Wiesner, S.A. and Wuest, T.

(2017), “'Industrie 4.0' and smart manufacturing-a review of research issues and application examples", International Journal of Automation Technology, Vol. 11 No. 1, pp. 4-16.

[43] Tamás, P., Illés, B. and Dobos, P. (2016), "Waste reduction possibilities for manufacturing systems in the industry 4.0", IOP Conference Series: Materials Science and Engineering, Vol. 161 No. 1, available at:

[44] Wang, S., Wan, J., Li, D. and Zhang, C. (2016a), "Implementing Smart Factory of Industrie 4.0: An Outlook", International Journal of Distributed Sensor Networks, Vol. 12 No. 1, p. 3159805.

[45] Vogel-Heuser, B. and Hess, D. (2016), "Industry 4.0-Prerequisites and Visions", IEEE Transactions on Automation Science and Engineering, Vol. 13 No. 2, pp. 411-413.

[46] Anderl, R. (2014), "Industrie 4.0 - Advanced Engineering of Smart Products and Smart Production", International Seminar on High Technology, No. October, pp. 1-14.r

[47] Liu, Y. and Xu, X. (2016), "Industry 4.0 and Cloud Manufacturing: A Comparative Analysis", Volume 2: Materials; Biomanufacturing; Properties, Applications and Systems; Sustainable Manufacturing, Vol. 139 No. March 2017, p. V002T04A016.

[48] Lu, Y. (2017), "Industry 4.0: A survey on technologies, applications and open research issues", Journal of Industrial Information Integration, Elsevier Inc., Vol. 6, pp. $1-10$.
[49] Mosterman, P.J. and Zander, J. (2016), "Industry 4.0 as a Cyber-Physical System study", Software and Systems Modeling, Springer Berlin Heidelberg, Vol. 15 No. 1, pp. 17-29.

[50] Müller, J.M., Buliga, O. and Voigt, K.I. (2018), "Fortune favors the prepared: How SMEs approach business model innovations in Industry 4.0", Technological Forecasting and Social Change, Elsevier, Vol. 132 No. December 2017, pp. $2-17$.

[51] Niesen, T., Houy, C., Fettke, P. and Loos, P. (2016), "Towards an integrative big data analysis framework for data-driven risk management in industry 4.0", Proceedings of the Annual Hawaii International Conference on System Sciences, Vol. 2016 No. March, pp. 5065-5074.

[52] Schlechtendahl, J., Keinert, M., Kretschmer, F., Lechler, A. and Verl, A. (2014), "Making existing production systems Industry 4.0-ready: Holistic approach to the integration of existing production systems in Industry 4.0 environments", Production Engineering, Vol. 9 No. 1, pp. 143-148.

[53] Wang, S., Wan, J., Li, D. and Zhang, C. (2016a), "Implementing Smart Factory of Industrie 4.0: An Outlook", International Journal of Distributed Sensor Networks, Vol. 12 No. 1, p. 3159805. 